\title{
IL-10 AND IL-35 AS INFLAMMATION REGULATORS IN PATIENTS WITH ALLERGIC RHINITIS AND MILD ATOPIC ASTHMA
}

\author{
Dr. Kremena Naydenova \\ Assistant Professor \\ Clinical Center of Allergology \\ University Hospital Alexandrovska \\ Medical University of Sofia, Sofia, Bulgaria \\ E-mail: kremenann@gmail.com \\ Dhttps://orcid.org/0000-0002-6805-2590 \\ Antoaneta Mihova \\ Biologist \\ Clinical Immunology Department \\ University Hospital Lozenetz \\ Sofia University, Sofia, Bulgaria \\ E-mail: toni02m@yahoo.com \\ iDhttps://orcid.org/0000-0002-7911-5147 \\ Alexander Kukov \\ Biologist \\ Clinical Immunology Department \\ University Hospital Lozenetz, Sofia, Bulgaria \\ E-mail: a_dimitroff@abv.bg \\ (iDhttps://orcid.org/0000-0002-2019-6202 \\ Dr. Tsvetelina Velikova \\ Assistant Professor \\ Clinical Immunology Department \\ University Hospital Lozenetz \\ Sofia University, Sofia, Bulgaria \\ E-mail: tsvelikova@medfac.mu-sofia.bg \\ (iDhttps://orcid.org/0000-0002-0593-1272
}

Received: September 22, 2021 Accepted: November 30, 2021 Online Published: January 06, 2022

DOI: 10.46545/aijbls.v4i1.229

URL: https://doi.org/10.46545/aijbls.v4i1.229

\begin{abstract}
Background. Significantly less is known about the immunoregulative cytokines, especially in allergic airway disease. This study aims to present the involvement of IL-35 and IL-10 in patients with allergic rhinitis (AR) and allergic bronchial asthma (BA). Methodology. The study comprised 71 patients $-A R$, patients with concomitant $A R$ and mild atopic $B A$, and healthy
\end{abstract}


controls (HC). We examined the serum levels of IL-35 and IL-10, along with other instrumental examinations, between March and September 2021. Findings. Levels of the regulatory cytokines IL-35 and IL-10 were significantly lower in patients than in HC $(87.19 \pm 11.90$ vs. 96.12 \pm 1.79 $\mathrm{pg} / \mathrm{ml}$; and $30.26 \pm 17.55 \mathrm{vs}$. $111.56 \pm 65.03 \mathrm{pg} / \mathrm{ml}$, respectively). Furthermore, threefold higher serum IL-10 levels were found in healthy subjects compared to patients $(p=0.006)$. No difference in the levels of interleukins was found between the studied groups. Conclusions. Our results indicate that elevated IL-35 and IL-10 may play an essential role in reducing the activity of underlying allergic inflammation in allergic respiratory diseases, although no difference in the levels of the studied cytokines was found between the different groups of patients. Therefore, we can speculate that the immunosuppressive cytokines IL-35 and IL-10 were involved in maintaining the healthy state of no inflammation.

Keywords: Allergic Rhinitis; Bronchial Asthma; IL- 35; IL-10; United Airway Disease.

JEL Classification Codes: I10, I11, I14.

\section{INTRODUCTION}

The prototypes of allergic diseases - allergic rhinitis (AR) and bronchial asthma (BA) are increasingly common disorders in the populations, leading to inferior quality of life. AR is one of the most common diseases worldwide and usually persists throughout life. Moreover, BA and AR often coexist (Barnes, 2008), where AR has been shown to be a significant risk factor for BA. Genetic predisposition and environmental factors also contribute to the development of allergic respiratory diseases.

In the immune system, there is a balance and regulation between T-helpers type 1 (Th) and type 2 cells (Th1/Th2 balance), as dysregulation leads to activation of one (Th1) or the other group of cells (Th2) and their respective cytokines released by them, resulting in autoimmune or allergic diseases (Romagnani, 2000). The importance of Th2cells and their cytokines for both the development of allergic sensitization and the pathogenesis of allergic inflammation has been well established and studied. While Th1 cells and their cytokines predominate in healthy individuals, Th2 type lymphocyte function predominates in patients with AR and atopic asthma.

Amongst the new players revealed to be a part of the Th cells balance is IL-35. It belongs to a relatively new class of inhibitory cytokines, including IL-10, transforming growth factor- $\beta$ (TGF- $\beta$ ), and the pleomorphic member of the cytokine family - IL-27 (Sawant \& Vignali, 2015). These suppressive cytokines are involved in immunomodulatory networks and channels that stimulate immune tolerance, which is essential for the normal functioning of the immune system (Sawant \& Vignali, 2015). Collison et al. (2007) characterize IL-35 as an immunosuppressive cytokine that mediates the conversion of naive $\mathrm{T}$ cells to induce $\mathrm{T}$ regulatory cells, Tregs (iTr) that function through it. At this stage of knowledge, two main categories of Tregs are known: natural, thymus-derived CD4 + CD25 + Foxp3 + Tregs (nTregs) and peripheral antigen-induced T regulatory cells (iTregs) (Lloyd \& Hawrylowicz, 2009). Induced T reg cells that secrete IL-10 are often called IL-10-Treg cells or Tr1 cells, whereas those that secrete TGF $\beta$ are termed Th3 cells (Hawrylowicz, 2005). iTregs are generated mainly by peripheral naive $\mathrm{T}$ cells in response to specific antigens or cytokine exposure (Dons et al., 2012).

There is data that IL-35 and IL-35-producing regulatory T cells (iTr35) cells inhibit reactions induced by Th2 in patients with AR (Liu et al., 2021). Precisely, a decrease in iTr35 has been observed in patients with AR. There was a significant reduction in the frequency of iTr35 and IL-35 expression levels in patients with asthma and allergy compared to patients 
without clinical symptoms and healthy individuals. There was also a gradual decrease of these cells with the severity of the disease (Wang et al., 2020). Studies show that iTr35 cells effectively regulate and maintain the immune response and immune tolerance to allergens in healthy individuals. However, their amounts and functions can be altered in patients with allergic diseases.

It is assumed that Tregs play a major role in maintaining immune tolerance by suppressing aberrant inflammatory cells or increasing the function of other regulatory and inhibitory cells (Pillai et al., 2011). These antigen-specific Treg cells secrete anti-inflammatory cytokines such as IL-10 and/or TGF $\beta$ and regulate the immune response in inflammation (Hawrylowicz \& O'Garra, 2005). IL-10 also inhibits the activation of many cell types and their effector functions associated with allergic disease. There is growing evidence that IL-10 acts as a general inhibitor of the proliferative and cytokine responses of Th1 and Th2 cells in vitro and in vivo (Del Prete et al., 1993). Akdis et al. (2004) show that the level of allergen-specific T cells (secreting IL-10) is significantly increased in non-allergic individuals compared to allergic ones. In contrast, the opposite is true for T cells producing the Th2-dependent cytokine IL-4.

Additionally, Kanai et al. (2017) attributed a leading role to IL-35 in an experimental model of asthma. Respiratory eosinophilia observed in pre-sensitized mice was severely suppressed by recombinant IL-35 (rIL-35). At the same time, elevated levels of chemokines (eotaxin-1 and eotaxin-2, CCL11 and CCL24) and subsequent airway eosinophilia are strongly antagonized by IL-35. Several studies have shown the anti-inflammatory function of IL-35 in several aspects of the pathogenesis of AR in vivo in a mouse model (Yokota et al., 2015; Huang et al., 2011; Dong et al., 2015). Significant relief of AR symptoms (such as nasal itching, sneezing, etc.) was observed when rIL-35 was administered in a model of mice with allergic rhinitis (Suzuki et al., 2017). Intranasal administration of IL-35 reduces the production of IL-4 and IL-5 associated with exacerbation of AR. IL-35-mediated IL-10 expression is also increased, stimulating Treg survival (Suzuki et al., 2017). Higher levels of IL-35 were observed in healthy controls due to the effective antiallergic mechanism present in daily sensitization by environmental allergens. This means that natural antiallergic mechanisms may contribute to the lower levels of IL-35 observed in allergic respiratory diseases (Chen et al., 2014).

The aim of our study was to evaluate and describe the involvement of inhibitory cytokines IL-35 and IL-10 and their regulatory role in the most common respiratory allergic diseases - AR and atopic BA.

\section{Participant (Subject) Characteristics}

\section{METHOD}

According to the Helsinki Declaration and local Ethics Committee's ethical guidelines, all participants gave written informed consent for the study (Protocol of approval from the National Program for Research "Young Scientists and Postdoctoral Students," Contract № D-95 / 26.02.2021; №8299/19.11.2019). Furthermore, all patients were informed about the purpose of the study.

AR was diagnosed if one or more of the following symptoms were present for more than 4 weeks: rhinorrhea, nasal obstruction, sneezing or itchy nose. In addition, conjunctivitis symptoms were often presented - injection of the conjunctiva, burning, itching, tearing of the eyes. A skin prick test was performed to confirm AR to assess atopy and correlate with nasal symptoms and allergy test results (Fig 3). 
The involvement of lower airways in patients with BA was assessed by examining forced expiratory volume for 1 second (FVC1) and participation of the small airways by evaluation FEF25-75 on spirometry. In addition, a detailed history, physical examination, skin allergy testing for sensitization and functional examination of respiration were performed in patients with lower respiratory tract symptoms.

The main inclusion criteria for the study participants were patients over 18 years of age with AR (intermittent/persistent). They were selected according to the criteria of Allergic Rhinitis and Impact on Asthma (ARIA) (Bousquet et al., 2001): 1. according to the duration of symptoms and severity is classified as intermittent - in the presence of symptoms less than 4 days a week or for less than 4 consecutive weeks and persistent, in the presence of symptoms more than 4 days a week or more than 4 consecutive weeks; 2 . as a mild is determined when there are no sleep disorders, daily activities, work and school, while in 3. moderate and 4. severe course sleep disorders or daily activities, sports or problems at work/school are observed.

Patients with mild atopic BA were evaluated according to the Global Initiative for Asthma (GINA, 2018): 1. Have asthma symptoms; 2. Performed respiratory function test meeting the criteria for BA; 3. Existing data on sensitization to inhaled allergens, established by skin prick test (wheal diameter $\geq 3 \mathrm{~mm}$ ). In addition, the severity of allergic asthma is assessed based on GINA criteria (GINA, 2020).

\section{Sampling Procedures}

Serum samples were collected from at least $6 \mathrm{ml}$ whole venous blood, taken in tubes containing EDTA, centrifuged at $1200 \mathrm{rpm}$ for 15 minutes, distributed in separate tubes and stored at - 70 • C. Before determining the protein level of IL-10 and IL-35, the samples were thawed entirely at room temperature. A solid-phase "sandwich" ELISA for in vitro quantification of cytokines in biological materials was used: Human IL-35 (Interleukin 35) ELISA Kit (Wuhan Fine Biotech Co., Ltd., Wuhan, China), with sensitivity 9,375 pg/ml; and Human Il-10 ELISA KIT (Diaclone SAS, France) with sensitivity $4.9 \mathrm{pg} / \mathrm{ml}$.

\section{Sample Size, Power, and Precision}

The study's principal investigators performed data collection according to the hospital's ethical and other policies and good clinical practice. The data were collected and coded uniformly to avoid any potential sources of bias. All the authors' efforts were implemented to address the potential bias. The statistical analysis was performed, omitting the empty entries in case of missing data (but no more than $5 \%$ of all data entries). There were no sensitivity analyzes in our study.

\section{Measures and Covariates}

We collected clinical data by physical examination, and instrumental methods (see below), as well as methods used to enhance the quality of the measurements (e.g., the training and reliability of assessors or the use of multiple observations).

\section{Research Design}

We conducted a prospective study from March 2021 to September 2021 at the Clinic of Allergology of the University Hospital "Alexandrovska" Sofia that included 71 patients over 18 years of age and 26 healthy controls. Of patients, 37 had allergic inflammation of the upper airways, manifested clinically by AR, and 34 people with AR and involvement of lower airways, 
clinically occurring with mild atopic BA. Clinical and demographic characteristics of patients are presented in Table 1.

\section{Experimental Manipulations or Interventions}

Rhinoscopy - examination of the nose was performed by rigid endoscopy, including assessment of the mucosal status - the presence of edema, patency of the nasal passages, mucosal color and other pathological changes.

Skin - allergy tests - a skin prick test (SPT) was performed to detect sensitization. Allergens from Stallergen (France) were used. The tested allergens were instilled on the skin on the front side of the forearm, the drops were pierced with a lancet on the surface with a depth of $1 \mathrm{~mm}$. An early reaction was sought, and the result was read in 20 minutes. A positive result was considered a diameter of erythema and papule $\geq 3 \mathrm{~mm}$. Control tests were also applied: negative control with saline is used and a positive control containing histamine hydrochloride (reported as such with a papule diameter $\geq 3 \mathrm{~mm}$ ).

The respiratory function test- is the gold standard test for objectifying bronchial obstruction, a mandatory criterion in BA. Therefore, we monitored the main spirometric parameters in the studied patients - FEV1- to determine bronchial obstruction. In addition, FEF25-75 was taken as an early marker of airway damage.

\section{Recruitment}

\section{RESULTS}

The study was cross-sectional, therefore, we did not follow-up the patients.

\section{Statistics and Data Analysis}

Statistical analyses of raw data (T-test, descriptive statistics, Kolmogorov-Smirnoff, MannWhitney, ANOVA, etc.) were performed by SPSS, IBM 2009, v.19. Significance level p <0.05 was considered significant.

\section{Baseline Data}

Baseline demographic and/or clinical characteristics of each group are provided in Table 1.

\section{Statistics and Data Analysis}

We found no differences between patients and healthy controls included in the study regarding gender and age. When assessing lung function by spirometry, a significant difference was found between the two groups of patients AR vs. AR+BA - FEV1 (100.56 \pm 10.99 vs. 85.62 $\pm 14.79, p$ $<0.001)$ and FEF25-75 (96.82 \pm 25.32 vs. $69.71 \pm 22.02, p<0.001)$. Patients with mild asthma and normal FEV1 may show impaired $\mathrm{FEF}_{25-75}$ only (Lipworth \& Clark 1997). In this regard, it has been demonstrated that $\mathrm{FEF}_{25-75}$ may be impaired more frequently than FEVI in patients suffering from allergic rhinitis (Ciprandi et al., 2005)

Table 1. Clinical and demographic characteristics of the patients participating in the study

\begin{tabular}{|l|l|l|l|l|}
\hline Features & $\begin{array}{l}\text { Patients with } \\
\text { AR }(\mathbf{n}=\mathbf{3 7})\end{array}$ & $\begin{array}{l}\text { Patients AR + } \\
\text { BA (n= 34) }\end{array}$ & $\begin{array}{l}\text { Healthy controls } \\
(\mathbf{n}=\mathbf{2 6})\end{array}$ & Significance, $\mathbf{p}^{*}$ \\
\hline Age (years) & $33.17 \pm 7.92$ & $33.43 \pm 8.56$ & $31.90 \pm 6.86$ & ns \\
\hline Sex & & & & \\
\hline
\end{tabular}




\begin{tabular}{|l|l|l|l|l|}
\hline Male & $26(70.3 \%)$ & $32(72.7 \%)$ & $16(61.54 \%)$ & ns \\
\hline Female of & $11(29.7 \%)$ & $12(27.3 \%)$ & $10(38.46 \%)$ & ns \\
\hline $\begin{array}{l}\text { FEV1 } \\
\text { predicted) }\end{array}$ & $100.56 \pm 10.99$ & $85.62 \pm 14.79$ & $107.42 \pm 11.21$ & $<0.001$ \\
\hline $\begin{array}{l}\text { FEF25-75 } \\
(\% \text { of predicted) }\end{array}$ & $96.82 \pm 25.32$ & $69.71 \pm 22.02$ & $95.69 \pm 17.35$ & $<0.001$ \\
\hline
\end{tabular}

FEV1, forced expiratory volume in one second;

FEF25-75 (\%), forced expiratory flow between $25 \%$ and $75 \%$ of vital capacity

*ANOVA analysis

We examined the cytokines IL-10 and IL-35 in patients with AR or AR and concomitant BA. The mean values of the two cytokines studied in the different groups of patients are presented in Table 1.

Table 2. Examined levels of IL-35 and IL-10 (pg/ml) in serum samples from healthy controls, all patients and individual groups with $\mathrm{AR}$ and $\mathrm{BA}+\mathrm{AR}$. Data are presented as mean $\pm \mathrm{SD}$ or $\mathrm{SE}$

\begin{tabular}{|c|c|c|c|c|c|c|c|}
\hline \multirow[t]{2}{*}{ Cytokines } & \multirow{2}{*}{$\begin{array}{l}\text { Healthy } \\
\text { people }\end{array}$} & \multicolumn{3}{|l|}{ Patients } & \multirow{2}{*}{$\begin{array}{l}\text { Healthy } \\
\text { vs. } \\
\text { patients }\end{array}$} & \multirow{2}{*}{$\begin{array}{l}\text { Healthy } \\
\text { vS. BA + } \\
\text { AR vS. } \\
\text { AR } \\
\text { (ANOVA) }\end{array}$} & \multirow{2}{*}{$\begin{array}{l}\mathbf{B A}+\mathbf{A R} \text { vS. } \\
\mathbf{A R}\end{array}$} \\
\hline & & Total & $\mathbf{B A}+\mathbf{A R}$ & AR & & & \\
\hline $\begin{array}{l}\mathrm{IL}-35, \\
\mathrm{pg} / \mathrm{ml}\end{array}$ & $\begin{array}{ll}96.12 \quad \pm \\
1.79 & \\
\end{array}$ & $\begin{array}{ll}87.19 & \pm \\
11.90 & \\
\end{array}$ & $\begin{array}{ll}88.55 \quad \pm \\
8.29\end{array}$ & $\begin{array}{ll}85.94 & \pm \\
14.45 & \end{array}$ & $\begin{array}{l}\mathrm{p} \\
<0.001\end{array}$ & $\mathrm{p}=0.057$ & $\mathrm{p}=0.350$ \\
\hline $\begin{array}{l}\mathrm{IL}-10, \\
\mathrm{pg} / \mathrm{ml}\end{array}$ & $\begin{array}{l}111.56 \quad \pm \\
65.03\end{array}$ & $\begin{array}{l}30.26 \quad \pm \\
17.55\end{array}$ & $\begin{array}{ll}32.76 & \pm \\
18.01 & \end{array}$ & $\begin{array}{l}27.96 \pm \\
17.04\end{array}$ & $\begin{array}{l}\mathrm{p}= \\
0.006\end{array}$ & $\mathrm{p}<0.001$ & $\mathrm{p}=0.254$ \\
\hline
\end{tabular}

Regarding the serum levels of IL-35 and IL-10, assessed in the serum of all included subjects, we found significant differences between the serum levels of healthy individuals and patients ( $\mathrm{p}<0.001 ; \mathrm{p}=0.006$, resp.) (Figure 1, a and b). IL-10 levels were more than three times higher in healthy individuals than those in patients.
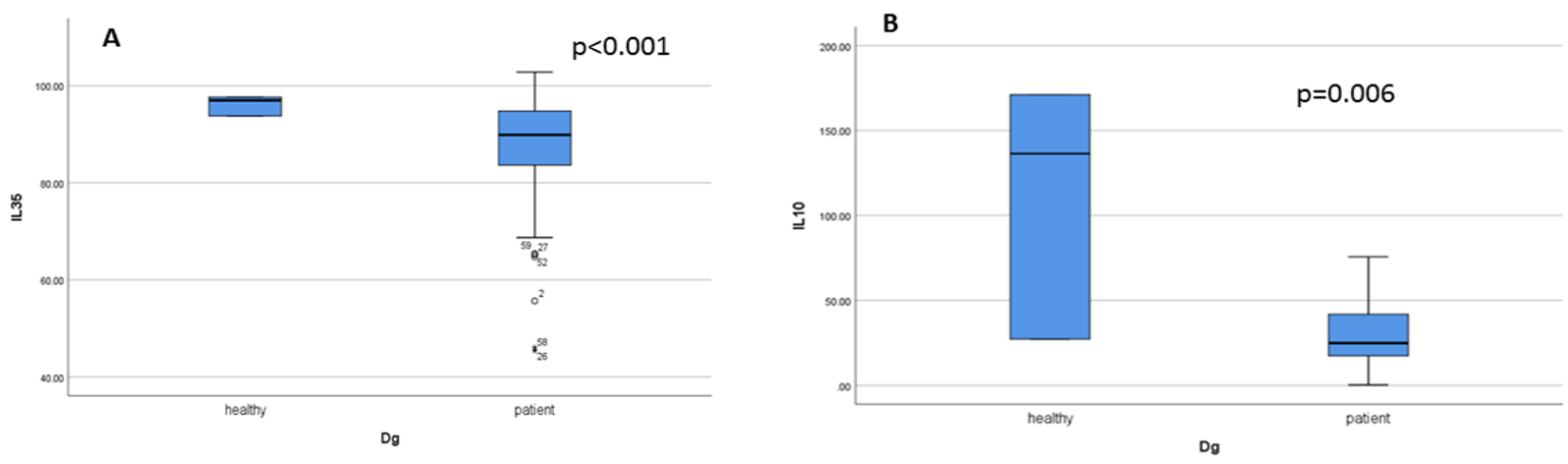

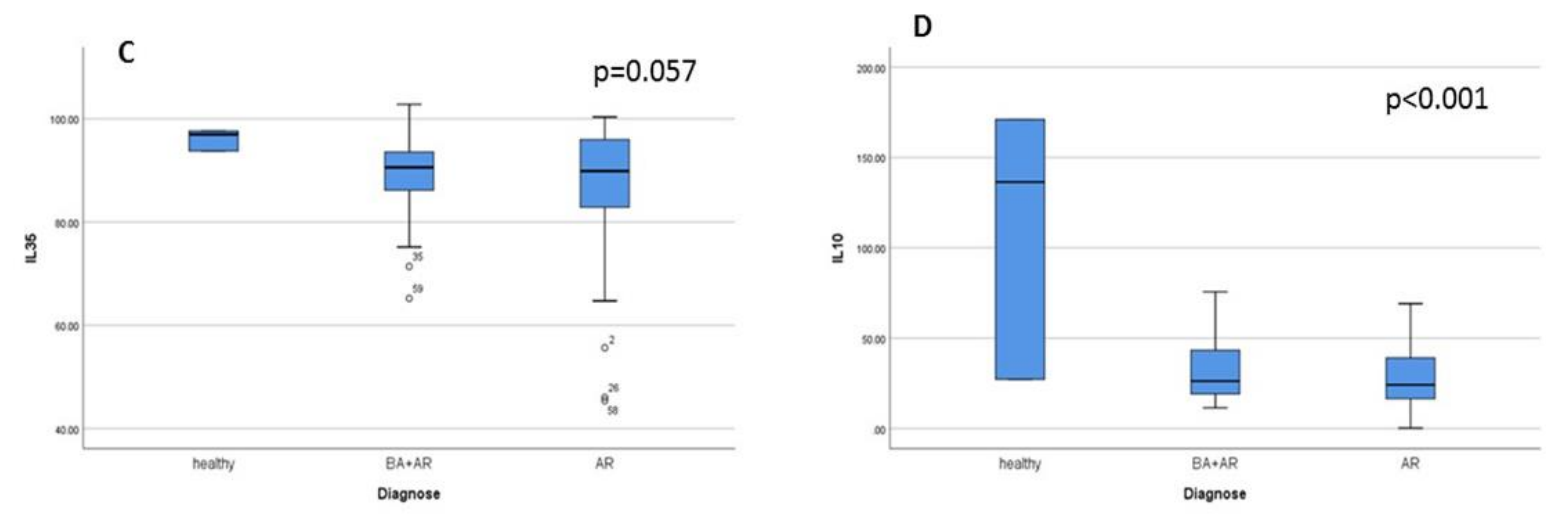

Figure 1. Levels of cytokines IL-35 (a) and IL-10 (b) in the serum of healthy controls vs. allergic patients, and levels of IL-35 (c) and IL-10 (d) vs. different groups of patients (BA+AR) and AR alone.

ANOVA analysis revealed differences between levels of both cytokines in healthy individuals and different groups of patients - with AR and BA and AR alone (IL-35, p <0.001 and IL-10, $p=0.057)$. Graphical representation of the data can be seen in Figure $1(\mathrm{c}, \mathrm{d})$.

There were no significant differences in IL-10 and IL-35 levels between the two BA + AR patients group and the AR group (Figure 1, c and d).

We found a significant correlation between the two serum cytokines, evaluated as strong $(\mathrm{r}=$ $0.863, \mathrm{p}=0.021)($ Figure 2).

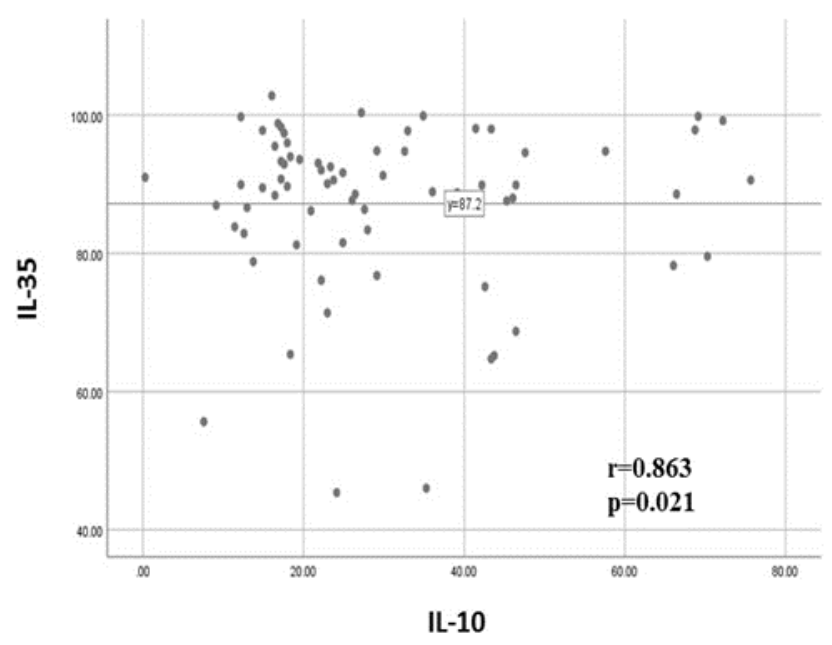

Figure 2. Correlation between serum cytokine levels of IL-35 and IL-10. The correlation was evaluated by the Pearson coefficient at the corresponding significance level (p).

The most common aeroallergens for patients with AR and BA+AR were house dust mite (32/71) and grasses (30/71). Other common allergens are presented in Fig.3. 


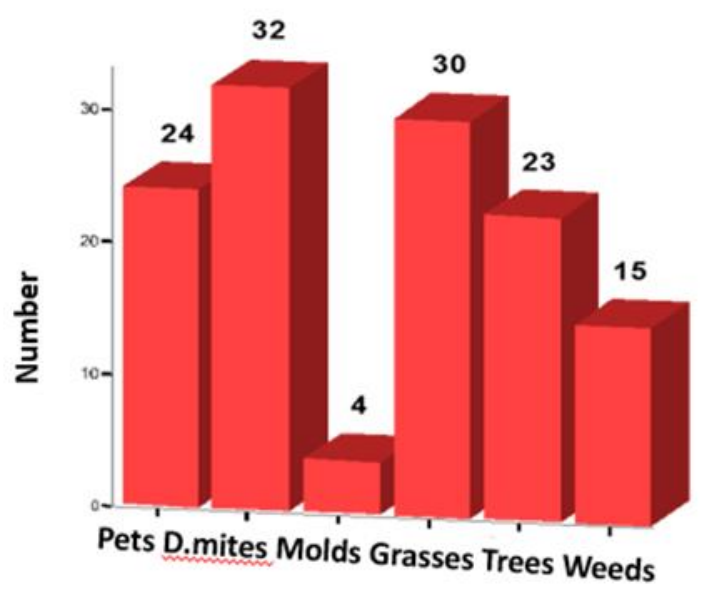

\begin{tabular}{ll}
\hline Allergens & Numbers \\
\hline Pets & 24 \\
Dust mites & 32 \\
Molds & 4 \\
Grasses & 30 \\
Trees & 23 \\
Weeds & 15 \\
\hline
\end{tabular}

Figure 3. Frequency distribution of the total number of the most common groups of allergens, determining the presence of atopy and the leading role of allergy in studied patients.

Figure 3 shows the most common aeroallergens to which the studied patients were sensitized, i.e., house dust mites and grass pollens, followed by pets, tree pollens and weeds.

\section{DISCUSSION}

This study aimed to evaluate and describe the relationship between AR and BA in terms of inhibitory cytokines participation in the allergic inflammation during united airway disease. IL35 and IL-10 and their regulatory role in the most common respiratory allergic diseases. It is known that AR and one of the phenotypes of BA are Th2-dominant disorders. Many studies show the association of Th2-based cytokines IL- 4, IL-5 and IL-13 with these diseases, but regarding IL-35 or IL-10, they are scarce.

We conducted a prospective study involving 71 patients with allergic inflammation of the upper airways, manifested by AR and involvement of the lower airways, clinically occurring with mild atopic BA. We found lower levels of regulatory cytokines IL-35 and IL-10 compared to healthy controls. However, no difference in the levels of the tested cytokines was found between the studied groups of patients with allergic respiratory diseases.

Experimental studies in mice suggest that IL-35 has immunosuppressive functions in allergic airway inflammation. The inflammatory response of lung tissue was strongly inhibited by recombinant IL-35 (rIL-35) injected intraperitoneally during sensitization by OVA-induced mice with asthma (Dong et al., 2015).

In this study, we found lower serum levels in the IL-35 ( $p<0.001)$ and IL-10 (p = 0.006) in patients compared to healthy subjects. Furthermore, IL-35 levels were lower in both groups of patients than controls. Indeed, low levels of IL-35, which has been shown to suppress Th2-mediated allergic airway inflammation (Yokota et al., 2015) and the IL-17-mediated immune response in patients with AR, lead us to believe that decreased IL-35 secretion plays a role in the pathogenesis of AR and BA.

As stated above, Treg cells are responsible for activating immune homeostasis with immune regulatory mechanisms, suppressing cytokines involved in Th1- and Th2-mediated responses and the allergic immune response (Vignali et al., 2008). In our study, IL-10 and IL-35 were used to determine Treg functions. Not surprisingly, serum levels of IL-35 and IL-10 were elevated in healthy individuals, with more than three-fold higher levels of IL-10 in healthy 
individuals observed, indicating the activity of the antiallergic regulatory mechanism of the immunomodulatory cytokine in individuals without underlying allergic disease.

In our study, patients with BA + AR showed significantly lower levels of IL-10 (32.76 \pm $18.01 \mathrm{pg} / \mathrm{ml})$ compared to healthy individuals $(111.56 \pm 65.03 \mathrm{pg} / \mathrm{ml} ; \mathrm{p}=0.006)$, which indicated the regulatory role of this cytokine in patients with allergic diseases.

However, we found no difference in serum levels of the two cytokines IL-35 and IL-10 between the two groups of patients, $\mathrm{AR}$ and $\mathrm{BA}+\mathrm{AR}$, probably due to the mild course of atopic BA. Given the limited number of human studies, Wang et al. showed that IL-35 suppresses IL-4 secretion in patients with allergic asthma and that IL-35 levels are lower than healthy controls (Wang et al., 2015). Furthermore, in studies by Bayrak Degirmenci et al. (2018) and Kouzaki et al. (2021), serum IL-35 levels were lower in patients with AR than in the control group.

IL-10 is one of the major regulatory cytokines in inflammatory reactions. Elevated levels of regulatory IL-10 and TGF- $\beta$ have been observed during allergen-specific immunotherapy (Vignali et al., 2008). Recent data highlight the role of regulatory B cells producing IL-10 and "protective" antibodies, which are likely to contribute to long-term tolerance (Shamji \& Durham, 2017). The group of patients with BA and concomitant AR is characterized by reduced concentrations of IL-10, as in our study. Lower IL-10 levels in patients with BA + AR lead us to think that there is decreased regulation of Treg cells.

Still, the role of Tregs remains unclear in AR patients. Recently, we reviewed the literature on the topic of upper respiratory tract inflammation in patients with AR that may contribute to lower respiratory airways' inflammation, where Th17 and Tregs balance is crucial (Naydenova et al., 2021). Both Th17 and Treg cells and related cytokines are involved in the immunological mechanism of AR along with the classical Th2 cells. Therefore, our results for decreased levels of Treg-related cytokines confirm the disturbed balance between Th17-Treg cells and again verify the concept of the united airway diseases.

In conclusion, IL-35 and IL-10 are critical anti-inflammatory cytokines. Their biological role includes decreased regulation of Th2 cells. Our study found both reduced in patients with $\mathrm{AR}$ or $\mathrm{AR}$ and BA compared to healthy controls. These findings suggest that inhibitory cytokines may exhibit antiallergic effects in treating allergic respiratory diseases.

\section{AUTHOR CONTRIBUTIONS}

Conceptualization: Kremena Naydenova and Tsvetelina Velikova

Data curation: Kremena Naydenova, Antoaneta Mihova, Alexander Kukov

Formal analysis: Tsvetelina Velikova

Funding Acquisition: Kremena Naydenova

Project Administration: Kremena Naydenova

Software: Tsvetelina Velikova

Validation: Tsvetelina Velikova

Writing - Original Draft: Kremena Naydenova

Writing - Review \& Editing: Kremena Naydenova and Tsvetelina Velikova

\section{CONFLICT OF INTEREST STATEMENT}

The authors declare that they have no competing interests. 


\section{ACKNOWLEDGMENTS}

This work is supported by the Bulgarian Ministry of Education and Science under the National Program for Research "Young Scientists and Postdoctoral Students."Contract № D-95 / 26.02.2021 with ent. №8299 / 19.11.2019

\section{REFERENCES}

Akdis, M., Verhagen, J., Taylor, A., Karamloo, F., Karagiannidis, C., Crameri, R., Thunberg, S., Deniz, G., Valenta, R., Fiebig, H., Kegel, C., Disch, R., Schmidt-Weber, C. B., Blaser, K., \& Akdis, C. A. (2004). Immune responses in healthy and allergic individuals are characterized by a fine balance between allergen-specific T regulatory 1 and T helper 2 cells. The Journal of experimental medicine, 199(11), 1567-1575. https://doi.org/10.1084/jem.20032058

Barnes P. J. (2008). The cytokine network in asthma and chronic obstructive pulmonary disease. The Journal of clinical investigation, 118(11), 3546-3556. https://doi.org/10.1172/JCI36130

Bayrak Degirmenci, P., Aksun, S., Altin, Z., Bilgir, F., Arslan, I. B., Colak, H., Ural, B., Solakoglu Kahraman, D., Diniz, G., Ozdemir, B., \& Kirmaz, C. (2018). Allergic Rhinitis and Its Relationship with IL-10, IL-17, TGF- $\beta$, IFN- $\gamma$, IL 22, and IL-35. Disease markers, 2018, 9131432. https://doi.org/10.1155/2018/9131432

Bousquet, J., Van Cauwenberge, P., Khaltaev, N., Aria Workshop Group, \& World Health Organization (2001). Allergic rhinitis and its impact on asthma. The Journal of allergy and clinical immunology, $108(5 \quad$ Suppl), $\quad$ S147-S334. https://doi.org/10.1067/mai.2001.118891

Chen C., Deng Y., Chen H., Wu X., Cheng S., Xu Y., Xiong W., Xie J.(2014). Decreased concentration of IL-35 in plasma of patients with asthma and COPD. Asian Pac.J. Allergy Immunol. 32, 211-217. https://doi.org/10.12932/AP0403.32.3.2014

Ciprandi, G., Cirillo, I., Vizzaccaro, A., Tosca, M., Passalacqua, G., Pallestrini, E., \& Canonica, G. W. (2005). Seasonal and perennial allergic rhinitis: is this classification adherent to real life?. Allergy, 60(7), 882-887. https://doi.org/10.1111/j.1398-9995.2005.00602.x

Collison, L. W., Workman, C. J., Kuo, T. T., Boyd, K., Wang, Y., Vignali, K. M., Cross, R., Sehy, D., Blumberg, R. S., \& Vignali, D. A. (2007). The inhibitory cytokine IL-35 contributes to regulatory T-cell function. Nature, 450(7169), 566-569. https://doi.org/10.1038/nature06306

Del Prete, G., De Carli, M., Almerigogna, F., Giudizi, M. G., Biagiotti, R., \& Romagnani, S. (1993). Human IL-10 is produced by both type 1 helper (Th1) and type 2 helper (Th2) T cell clones and inhibits their antigen-specific proliferation and cytokine production. Journal of immunology (Baltimore, Md. : 1950), 150(2), 353-360.

Dong, J., Wong, C. K., Cai, Z., Jiao, D., Chu, M., \& Lam, C. W. (2015). Amelioration of allergic airway inflammation in mice by regulatory IL-35 through dampening 
inflammatory dendritic cells. Allergy, 70(8), 921-932. https://doi.org/10.1111/all.12631

Dons, E. M., Raimondi, G., Cooper, D. K., \& Thomson, A. W. (2012). Induced regulatory T cells: mechanisms of conversion and suppressive potential. Human immunology, 73(4), 328-334. https://doi.org/10.1016/j.humimm.2011.12.011

Global Initiative for Asthma. GINA Report, global strategy for asthma management and prevention. Retrieved from http://www.ginasthma.org

Hawrylowicz C. M. (2005). Regulatory T cells and IL-10 in allergic inflammation. The Journal of experimental medicine, 202(11), 1459-1463.

Hawrylowicz, C. M., \& O'Garra, A. (2005). Potential role of interleukin-10-secreting regulatory $\mathrm{T}$ cells in allergy and asthma. Nature reviews. Immunology, 5(4), 271-283. https://doi.org/10.1038/nri1589

Huang, C. H., Loo, E. X., Kuo, I. C., Soh, G. H., Goh, D. L., Lee, B. W., \& Chua, K. Y. (2011). Airway inflammation and IgE production induced by dust mite allergen-specific memory/effector Th2 cell line can be effectively attenuated by IL-35. Journal of immunology (Baltimore, $\quad$ Md.: 1950), $187(1), \quad 462-471$. https://doi.org/10.4049/jimmunol.1100259

Kanai, K., Park, A. M., Yoshida, H., Tsunoda, I., \& Yoshie, O. (2017). IL-35 Suppresses Lipopolysaccharide-Induced Airway Eosinophilia in EBI3-Deficient Mice. Journal of immunology (Baltimore, Md.: 1950), 198(1), https://doi.org/10.4049/jimmunol.1600506

Kouzaki, H., Arai, Y., Nakamura, K., Murao, T., Tojima, I., Shimizu, S., Yuta, A., \& Shimizu, T. (2021). Anti-inflammatory roles of interleukin-35 in the pathogenesis of Japanese cedar pollinosis. Asia Pacific allergy, 11(3), e34. https://doi.org/10.5415/apallergy.2021.11.e34

Lipworth, B. J., \& Clark, D. J. (1997). Effects of airway calibre on lung delivery of nebulised salbutamol. Thorax, 52(12), 1036-1039. https://doi.org/10.1136/thx.52.12.1036

Liu, W., Zeng, Q., Wen, Y., Tang, Y., Yan, S., Li, Y., Zhou, L., \& Luo, R. (2021). Inhibited interleukin 35 expression and interleukin 35-induced regulatory $\mathrm{T}$ cells promote type II innate lymphoid cell response in allergic rhinitis. Annals of allergy, asthma \& immunology : official publication of the American College of Allergy, Asthma, \& Immunology, 126(2), 152-161.e1.https://doi.org/10.1016/j.anai.2020.08.005

Lloyd, C. M., \& Hawrylowicz, C. M. (2009). Regulatory T cells in asthma. Immunity, 31(3), 438-449. https://doi.org/10.1016/j.immuni.2009.08.007

Naydenova, K.; Dimitrov, V.; Velikova, T. (2021).Immunological and microRNA Features of Allergic Rhinitis in the Context of United Airway Disease. Sinusitis, 5, 45-52. 
https://doi.org/10.3390/sinusitis5010005

Pillai, M. R., Collison, L. W., Wang, X., Finkelstein, D., Rehg, J. E., Boyd, K., SzymczakWorkman, A. L., Doggett, T., Griffith, T. S., Ferguson, T. A., \& Vignali, D. A. (2011). The plasticity of regulatory $\mathrm{T}$ cell function. Journal of immunology (Baltimore, $\mathrm{Md}$. : 1950), 187(10), 4987-4997. https://doi.org/10.4049/jimmunol.1102173

Romagnani S. (2000). T-cell subsets (Th1 versus Th2). Annals of allergy, asthma \& immunology : official publication of the American College of Allergy, Asthma, \& Immunology, 85(1), 9-21. https://doi.org/10.1016/S1081-1206(10)62426-

Sawant, D.V., Hamilton, K., \& Vignali, D. A. (2015). Interleukin-35: Expanding Its Job Profile. Journal of interferon \& cytokine research : the official journal of the International Society for Interferon and Cytokine Research, 35(7), 499-512. https://doi.org/10.1089/jir.2015.0015

Shamji, M. H., \& Durham, S. R. (2017). Mechanisms of allergen immunotherapy for inhaled allergens and predictive biomarkers. The Journal of allergy and clinical immunology, 140(6), 1485-1498. https://doi.org/10.1016/j.jaci.2017.10.010

Suzuki, M., Yokota, M., Nakamura, Y., Ozaki, S., \& Murakami, S. (2017). Intranasal administration of IL-35 inhibits allergic responses and symptoms in mice with allergic rhinitis. Allergology international: official journal of the Japanese Society of Allergology, 66(2), 351-356. https://doi.org/10.1016/j.alit.2016.08.014

Vignali, D. A., Collison, L. W., \& Workman, C. J. (2008). How regulatory T cells work. Nature reviews. Immunology, 8(7), 523-532. https://doi.org/10.1038/nri2343

Wang, W., Li, P., Chen, Y. F., \& Yang, J. (2015). A potential immunopathogenic role for reduced IL-35 expression in allergic asthma. The Journal of asthma : official journal of the Association for the Care of Asthma, 52(8), 763-771. https://doi.org/10.3109/02770903.2015.1038390

Wang, W., Wei, C., Cheng, Z., \& Yang, J. (2020). Aberrant Th2 Immune Responses Are Associated With a Reduced Frequency of IL-35-Induced Regulatory T Cells After Allergen Exposure in Patients With Allergic Asthma. Allergy, asthma \& immunology research, 12(6), 1029-1045. https://doi.org/10.4168/aair.2020.12.6.1029

Yokota, M., Suzuki, M., Nakamura, Y., Ozaki, S., \& Murakami, S. (2015). Cytokine modulation by IL-35 in mice with allergic rhinitis. American journal of rhinology \& allergy, 29(4), 251-256. https://doi.org/10.2500/ajra.2015.29.4188

\section{Copyrights}

Copyright for this article is retained by the author(s), with first publication rights granted to the journal. This is an open-access article distributed under the terms and conditions of the Creative Commons Attribution license (http://creativecommons.org/licenses/by/4.0/) 